\title{
VALIDASI ST EUROPEAN QUALITY OF LIFE-5 DIMENSIONS (EQ-5D) VERSI INDONESIA PADA PASIEN HIPERTENSI DI PUSKESMAS KOTAGEDE II YOGYAKARTA
}

\section{VALIDATION OF EUROPEAN QUALITY OF LIFE ST-5 DIMENSIONS (EQ-5D) INDONESIA VERSIONS OF HYPERTENSION PATIENTS IN HEALTH CARE CENTER KOTAGEDE II YOGYAKARTA}

\author{
Andriana Sari, Nidia Yuni Lestari, Dyah Aryani Perwitasari \\ Fakultas Farmasi Universitas Ahmad Dahlan \\ Jln. Prof. Dr. Soepomo, Janturan, Yogyakarta, Telp. (0274) 379418
}

Email: andriesari@gmail.com

Submitted : 22-08-2015

Reviewed : 07-09-2015

Accepted:.25-11-2015

\begin{abstract}
ABSTRAK
Hipertensi merupakan faktor risiko utama terjadinya kematian akibat penyakit tidak menular di dunia. Dalam World Health Statistics tahun 2012, WHO melaporkan bahwa sekitar 51\% dari kematian akibat stroke dan $45 \%$ dari penyakit jantung koroner disebabkan oleh hipertensi. Pasien dengan obsesitas, hipertensi, dan diabetes dapat memperburuk kualitas hidup pasien baik secara fisik dan status mental. Sehingga perlu dilakukan pengukuran untuk menilai kualitas hidup dengan European Quality of Life-5 Dimensions (EQ-5D) questioner. Penelitian ini bertujuan untuk mengetahui validitas dan reliabilitas EQ-5D versi Indonesia sebagai instrumen untuk mengukur kualitas hidup pasien hipertensi di Puskesmas Kotagede II Yogyakarta. Metode penelitian yang digunakan adalah observasional deskriptif. Pengambilan data dilakukan dengan menggunakan kuesioner yang dilakukan pada waktu tertentu. Instrumen yang digunakan dalam penelitian ini adalah EQ-5D yang sudah diterjemahkan ke dalam versi Indonesia. Populasi terjangkau dalam penelitian ini adalah semua pasien hipertensi di di Puskesmas Kotagede II Yogyakarta bulan Mei sampai Juni 2014. Sampel dalam penelitian adalah yang sesuai dengan kriteria inklusi dan kriteria eksklusi. Analisa terhadap validitas menggunakan validitas kontruk dengan metode pearson. Uji reliabilitas menggunakan metode Cronbach alpha coefficient. Analisa terhadap 51 pasien Hipertensi diperoleh hasil koefisien pearson korelasi diatas 0,30, sehingga dapat disimpulkan instrumen kuisioner EQ-5D versi Indonesia tersebut valid. Hasil Cornbach's $\alpha$ adalah 0.718 sehingga dapat disimpulkan instrumen kuisioner EQ-5D versi Indonesia tersebut reliable.
\end{abstract}

Kata kunci: hipertensi, kualitas hidup $E Q-5 D$ kuisioner, validitas, reabilitas

\begin{abstract}
Hypertension is a major risk factor for the occurrence of deaths from non-communicable diseases in the world. In the World Health Statistics 2012, WHO reported that approximately $51 \%$ of deaths from stroke and $45 \%$ of coronary heart disease due to hypertension. Patients with obsesitas, hypertension, and diabetes can worsen patient's quality of life both physically and mental status. This study aims to assess the quality of life by the European Quality of Life-5 Dimensions (EQ-5D) questionnaire. This study aims to determine the validity and reliability of the EQ-5D in Indonesian version as an instrument for measuring the quality of life of patients with hypertension in the Health Center Kotagede II Yogyakarta. The method of this study was descriptive observational. Data were collected using a questionnaire conducted at a particular time. The instrument used in this study is the EQ-5D which has been translated into Indonesian. Affordable population in this study were all patients with hypertension in Health Center Kotagede II Yogyakarta at May to June 2014. The sample in this
\end{abstract}


study are in accordance with the criteria for inclusion and exclusion criteria. Analysis of the validity was construct's validity with Pearson method. Test reliability was Cronbach's alpha coefficient. From the data analysis for 51 patients Hypertension Pearson correlation coefficient obtained results are above 0.30, so it can be concluded instrument EQ-5D questionnaire Indonesian version is valid. Results Cornbach's $\alpha$ is 0718 so it can be concluded instrument EQ-5D questionnaire Indonesian version is reliable.

Keywords: hypertension, quality of life EQ-5D questionnaire, validity, reliability

\section{PENDAHULUAN}

World Health Statistics tahun 2012 melaporkan bahwa sekitar 51\% dari kematian akibat stroke dan $45 \%$ dari penyakit jantung koroner disebabkan oleh hipertensi. Prevalensi hipertensi akan terus meningkat, dan diprediksi pada tahun 2025 sebanyak 29\% orang dewasa di seluruh dunia terkena hipertensi. Proporsi laki-laki dengan hipertensi 31,3\%, sedangkan perempuan 31,9\%. Menurut data Registry Acute Heart Failure Rumah Sakit Jantung Harapan Kita Jakarta sebanyak 28\% kasus gagal jantung dan 50\% Coronary Artery Disease (CAD) disebabkan oleh hipertensi.

Terdapat empat dimensi mengenai kualitas hidup meliputi kesehatan fisik, kesejahteraan psikologis, hubungan social, dan hubungan dengan lingkungan (Fitriana \& Ambarini, 2012). Manfaat dari mengetahui kualitas hidup pasien adalah untuk meningkatkan kualitas terapi (Spilker, 1996). Hasil studi sistematik review dan metaanalisa terhadap hubungan kualitas hidup dengan hipertensi diketahui sebagian besar dari 20 studi yang dipilih untuk tinjauan sistematis mengidentifikasi kualitas hidup yang rendah pada pasien dengan hipertensi, tetapi sangat heterogen dalam hal kriteria seleksi dan kelompok pembanding, membatasi validitas eksternal mereka (Trevisol DJ et al, 2011). Salah satu kuesioner untuk menilai kualitas hidup adalah formulir European Quality of Life-5 Dimensions (EQ$5 D$ ) yang dikeluarkan oleh EuroQol dari Inggris. Kuesioner ini telah digunakan di banyak negara termasuk Indonesia, dan dapat digunakan di berbagai populasi termasuk pada usia lanjut (Anissa, 2013).

EQ-5D telah banyak diterjemahkan dan divalidasi di beberapa negara untuk mengukur kualitas hidup pada pasien dengan berbagai penyakit misal di Inggris pada pasien dengan penyakit kanker paru (Pickard et all, 2007), pasien dengan stroke, nyeri tulang belakang, investigasi kolposkopi (Whynes, 3013) dan di Indonesia pada pasien usia lanjut (Setiati, 2010 dan Anissa, 2013). Validitas menunjukkan seberapa nyata suatu pengujian mengukur apa yang seharusnya diukur (Hartono, 2004). Reliabilitas ialah indeks yang menunjukkan sejauh mana suatu alat pengukur dapat dipercaya atau dapat diandalkan. Hal ini berarti menunjukkan sejauh mana hasil pengukuran itu tetap konsisten atau tetap asas (ajeg) bila dilakukan pengukuran dua kali atau lebih terhadap gejala yang sama, dengan menggunakan alat ukur yang sama (Notoatmodjo, 2012).

Hipertensi diketahui merupakan penyebab utama prognosis penyakit gagal jantung, Coronary Artery Disease (CAD), dan stroke yang dapat menimbulkan penurunan kualitas hidup pasien bahkan kematian. Sehingga tujuan penelitian ini untuk menguji validitas dan reliabilitas EQ-5D versi Indonesia sebagai instrumen untuk mengukur kualitas hidup pasien hipertensi agar data yang dihasilkan valid, reliabel dan dapat dipertanggungjawabkan.

\section{METODE PENELITIAN}

Jenis penelitian ini merupakan penelitian observasional deskriptif. Pengambilan data dilakukan dengan menggunakan kuesioner yang dilakukan pada waktu tertentu. Data sosiodemografi pasien yang meliputi usia, jenis kelamin, serta pendidikan dikumpulkan dari catatan atau rekam medis dari responden. Peneliti dalam mengumpulkan data mengenai kualitas hidup menggunakan data primer. Sumber data primer diperoleh dari subjek penelitian dengan menggunakan instrumen yaitu EQ-5D versi Indonesia. Instrumen mengacu pada penelitian sebelumnya yang telah dilakukan oleh Annisa (2013) untuk mengembangkan validasi kuesioner EQ-5D versi Indonesia. Kuesioner tersebut digunakan untuk mengukur kualitas hidup pasien usia lanjut di Klub Jantung Sehat.

Populasi target dalam penelitian ini adalah semua pasien hipertensi di di Puskesmas Kotagede II Yogyakarta. Populasi terjangkau dalam penelitian ini adalah semua pasien hipertensi di Puskesmas 
Kotagede II Yogyakarta bulan Mei sampai Juni 2014. Sampel dalam penelitian adalah yang sesuai dengan kriteria inklusi dan kriteria eksklusi. Kriteria inklusi meliputi Pasien hipertensi, usia 17-65 tahun, bersedia terlibat dalam penelitian dan tidak buta huruf. Kriteria eksklusi yaitu pasien HIV/AIDS, pasien kanker, pasien dengan gangguan ginjal, dan pasien chirosis hepatik dengan hipertensi portal. Uji reliabilitas pada penelitian ini menggunakan metode Cronbach alpha coefficient. Uji validitas pada penelitian ini menggunakan validitas isi, menggunakan korelasi Pearson Product Moment atau yang sering disebut dengan korelasi pearson. Validitas isi terpenuhi jika koefisien pearson korelasi diatas 0,30 (Nugroho, 2010).

\section{HASIL DAN PEMBAHASAN}

Penelitian ini dilakukan menggunakan metode penelitian observasional deskriptif dimana pengambilan data dilakukan dengan menggunakan kuesioner yang dilakukan pada waktu tertentu. Instrumen yang digunakan dalam penelitian ini adalah EQ-5D yang sudah diterjemahkan ke dalam versi Indonesia. Sesuai dengan tujuan penelitian yaitu untuk mengetahui validitas dan reliabilitas EQ5D versi Indonesia sebagai instrumen untuk mengukur kualitas hidup pasien hipertensi maka penelitian dilakukan di pusat pelayanan kesehatan di Puskesmas Kotagede II Yogyakarta pada periode penelitian bulan Mei sampai Juni 2014.

Sampel dalam penelitian adalah yang sesuai dengan kriteria inklusi dan kriteria eksklusi. Selama periode penelitian diperoleh data subjek penelitian sebanyak 28 pasien hipertensi dan 23 pasien hipertensi dengan komplikasi, sehingga total pasien adalah 51 pasien.

Tabel I. Karakteristik pasien hipertensi di Puskesmas Kotagede II Yogyakarta

\begin{tabular}{lc}
\hline Karakteristik & Persentase (\%) \\
\hline Jenis Kelamin & \\
Laki-laki & $33 \%$ \\
Perempuan & $67 \%$ \\
Usia & \\
$\quad<45$ tahun & $2 \%$ \\
$45<=x<=60$ & $39 \%$ \\
$>60$ & $59 \%$ \\
Jenis Pekerjaan & \\
Tidak Bekerja & $57 \%$ \\
Pensiunan & $21 \%$ \\
Wiraswasta & $20 \%$ \\
Pegawai Swasta & $2 \%$ \\
Pegawai Negeri/ABRI & $0 \%$ \\
Pendidikan & \\
Tidak Tamat SD & $14 \%$ \\
Tamat SD & $22 \%$ \\
Tamat SLTP & $18 \%$ \\
Tamat SLTA/Sederajat & $36 \%$ \\
Tamat Akademi & $4 \%$ \\
Tamat S1 & $6 \%$ \\
Penghasilan & \\
<500.000/bulan & $12 \%$ \\
500.000-2 juta/bulan & $17 \%$ \\
2-6 juta/bulan & $12 \%$ \\
Tidak memberikan data & $59 \%$ \\
\hline
\end{tabular}

Diketahui dari karakteristik pasien diketahui pasien terbanyak memiliki jenis kelamin perempuan. Jumlah ini sejalan dengan penelitian sebelumnya yang dilakukan oleh Adyani (2008) sebanyak $71,11 \%$ perempuan dan $28,88 \%$ laki-laki. Rerata usia terbanyak pada usia lebih dari 60 tahun atau lanjut usia dimana kebanyakan pasien tersebut tidak bekerja. Apabila melihat karakteristik pendidikan maka tersebar tingkat pendidikan dan paling tinggi pada tamat SLTA/Sederajat. Pada saat 
pengisian data penghasilan $59 \%$ pasien tidak memberikan data dan sejumlah $17 \%$ memiliki penghasilan 500.000-2 juta/bulan.

Uji reliabilitas pada penelitian ini menggunakan metode Cronbach alpha coefficient untuk menentukan apakah setiap instrumen reliabel atau tidak. Suatu instrumen dikatakan reliabel jika nilai cronbach alpha $\geq 0,70$. Hal ini sesuai dengan Kategori indeks reliabilitas menurut Suharsimi (1998) dapat dibedakan menjadi beberapa tingkatan yaitu: 0,8 - 1 (sangat tinggi); 0,2 - 0,4 (rendah); 0,6 - 0,8 (tinggi); 0 - 0,2 (sangat rendah); 0,4-0,6 (cukup).

Tabel II. Hasil uji reabilitas kuesioner EQ-5D versi Indonesia

\begin{tabular}{ll}
\hline Reliability Statistics & \\
\hline Cronbach's Alpha & N of Items \\
.718 & 5 \\
\hline
\end{tabular}

Dari hasil analisa data menggunakan SPPS terhadap 51 pasien Hipertensi diperoleh hasil nilai Cornbach's $\alpha$ adalah 0,718 sehingga dapat disimpulkan instrumen kuisioner EQ-5D versi Indonesia tersebut reliable.

Jenis validitas pada penelitian ini menggunakan validitas isi. Suatu instrumen disebut valid atau tidak menurut validitas isi jika isi instrumen tersebut telah merupakan sampel yang representatif dari keseluruhan yang akan diukur. Pengujian validitas isi menggunakan korelasi antar skor baris butir dengan skor total menggunakan korelasi Pearson Product Moment atau yang sering disebut dengan korelasi pearson. Validitas isi terpenuhi jika koefisien pearson korelasi diatas 0,30 dan jika tidak terpenuhi butir tersebut harus diperbaiki atau dibuang (Nugroho, 2010).

Tabel III. Hasil uji validitas kuesioner EQ-5D versi Indonesia

\begin{tabular}{lll}
\hline Dimensi Pertanyaan & $\begin{array}{l}\text { Koefisien } \\
\text { korelasi }\end{array}$ & pearson \\
\hline Berjalan/Bergerak (BB) & 0,753 & Validitas \\
Perawatan Diri (PD) & 0,472 & Valid \\
Kegiatan yang Biasa Dilakukan (KBS) & 0,732 & Valid \\
Rasa Kesakitan/ Tidak Nyaman (RS/RTN) & 0,730 & Valid \\
Rasa Cemas/ Depresi (Sedih) (RC/D) & 0,771 & Valid \\
\hline
\end{tabular}

Nilai skor baris butir dengan skor total menunjukkan nilai koefisien pearson korelasi diatas 0,30 tanpa terkecuali. Sehingga, dapat disimpulkan instrumen kuesioner EQ-5D versi Indonesia tersebut valid. Hasil penelitian kami serupa dengan penelitian yang dilakukan Stark et al (2010) dimana EQ5D menunjukkan hasil yang valid, terpercaya, dan responsif kesehatan pada pasien penyakit crohn (CD) dan ulcerative colitis (UC). Penelitian lain pada penyakit cystic fibrosis dilakukan oleh EidtKoch D,et al ( 2009) EQ-5D-Y dapat digunakan sebagai instrumen generik yang valid secara crosssectional mencerminkan perbedaan kesehatan sesuai dengan perkembangan penyakit kronis seumur hidup dari cystic fibrosis.

Kekuatan hubungan antar variabel ditunjukkan melalui nilai korelasi. Dapat dilihat padaTabel IV.

Tabel IV. Tingkat keeratan hubungan variabel $\mathbf{X}$ dan variabel Y (Muhidin, 2007)

\begin{tabular}{ll} 
Nilai Korelasi & Keterangan \\
\hline $0,00-<0,20$ & Hubungan sangat lemah (diabaikan/dianggap tidak ada) \\
$\geq 0,20-<0,40$ & Hubungan rendah \\
$\geq 0,40-<0,70$ & Hubungan sedang / cukup \\
$\geq 0,70-<0,90$ & Hubungan kuat / tinggi \\
$\geq 0,90-\leq 1,00$ & Hubungan sangat kuat / tinggi \\
\hline
\end{tabular}


Tabel V. Data know group validity

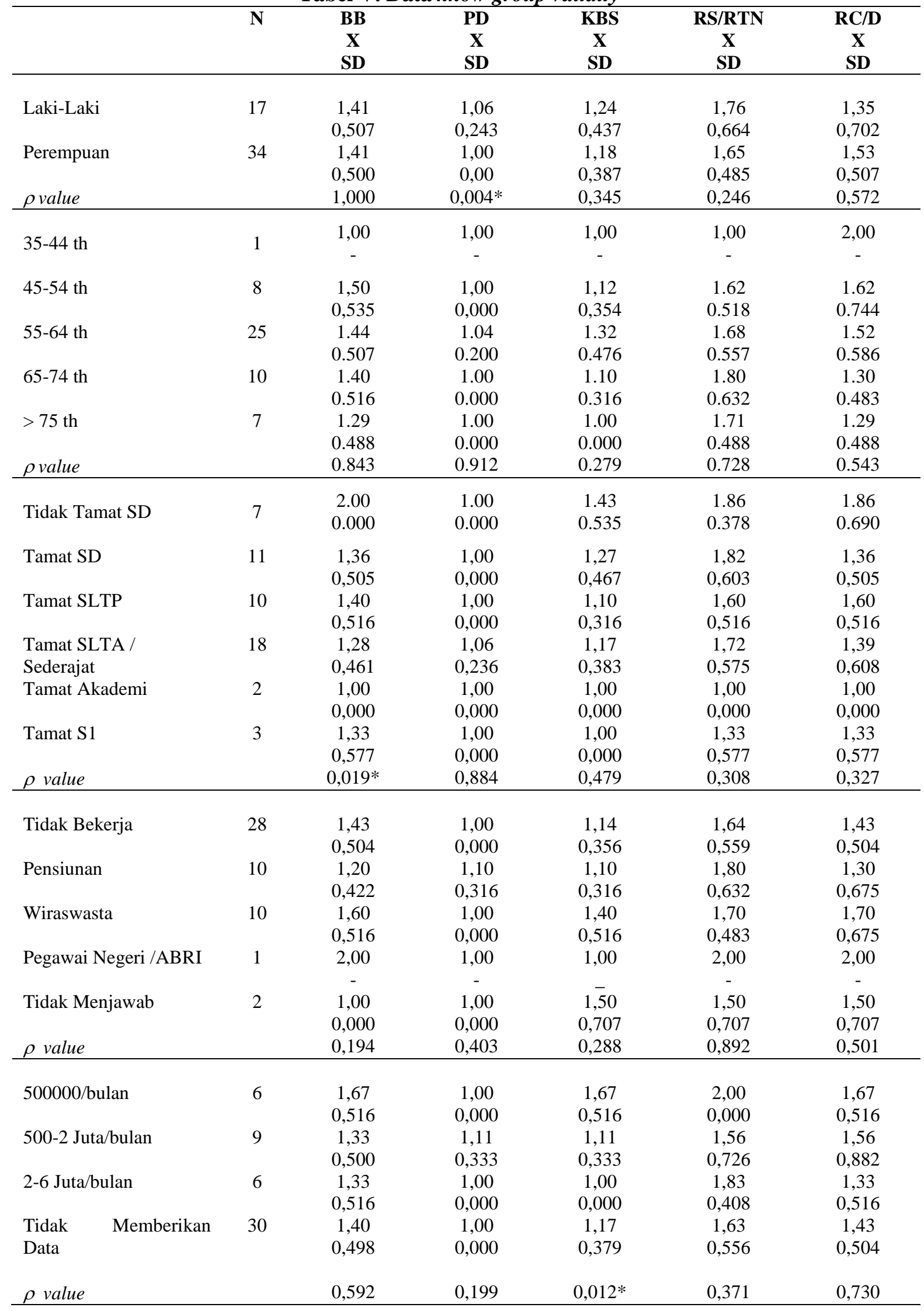

$*$ nilai $\rho \leq 0,05$ adanya perbedaan bermakna terhadap kelompok yang diujikan 
Pada Tabel III dapat dilihat pearson korelasi setiap dimensi. Untuk dimensi perawatan diri diperoleh pearson korelasi sebesar 0,472 ini menunjukkan tingkat keeratan hubungan antara variabel sedang/cukup. Dimensi berjalan/bergerak, kegiatan yang biasa dilakukan, rasa kesakitan/ tidak nyaman, rasa cemas/depresi (sedih) memiliki nilai Pearson korelasi berturut-turut sebesar 0,753; 0,$732 ; 0,730 ; 0,771$. Sehingga, dapat diketahui tingkat keeratan hubungan antara variabel kuat/tinggi. Hasil know group validity karakteristik pasien terhadap validitas kuisioner dapat dilihat pada Tabel V.

Untuk mengetahui apakah kuesioner EQ-5D versi Indonesia dapat membedakan kualitas hidup pasien atau tidak sehingga dapat diketahui validitas tiap item pertanyaan dari kuisioner maka digunakan nilai signifikasi hasil analisa Know Group Validity. Jika diketahui nilai $\rho \geq 0,05$ artinya tidak ada perbedaan bermakna dan jika nilai $\rho \leq 0,05$ adanya perbedaan bermakna terhadap kelompok yang diujikan.

Setelah dilakukan analisis data didapatkan hasil yang menunjukkan bahwa kuesioner tersebut hasilnya terdapat adanya perbedaan signifikan pada kelompok yang membedakan antara jenis kelamin pada dimensi perawatan diri, pendidikan pada dimensi berjalan/bergerak dan penghasilan pasien pada dimensi kegiatan yang biasa dilakukan. Tetapi, tidak ada perbedaan yang signifikan pada kelompok lainnya meskipun diujikan pada dua kelompok yang berbeda. Sehingga kuesioner EQ-5D versi Indonesia diketahui valid dapat digunakan untuk membedakan kualitas hidup pasien berdasarkan jenis kelamin pada dimensi perawatan diri, tingkat pendidikan pada dimensi berjalan/bergerak, dan tingkat penghasilan pada dimensi kegiatan yang biasa dilakukan.

\section{KESIMPULAN}

Uji reliabilitas menunjukkan nilai Cronbach Alpha Coefficient $\geq 0,70$ yaitu 0,718 artinya kuesioner EQ-5D versi Indonesia reliabel. Uji validitas setiap dimensi menunjukkan nilai Pearson Corellation Coefficient $\geq 0,30$ artinya kuesioner EQ-5D versi Indonesia valid. Instrumen kuesioner EQ-5D versi Indonesia merupakan instrumen yang valid dan reliabel untuk mengukur kualitas hidup pasien hipertensi di Puskesmas Kotagede II Yogyakarta.

\section{SARAN}

Instrument kuisioner EQ-5D versi Indonesia dapat mengetahui perbedaan kualitas hidup pada pasien hipertensi dengan komplikasi dan hipertensi tanpa komplikasi.

\section{KETERBATASAN PENELITIAN}

Penelitian yang telah dilakukan memiliki beberapa keterbatasan terkait dengan jumlah sampel yang diambil, tempat pengambilan sampel, teknik pengambilan sampel, keterbatasan literatur dan publikasi karya ilmiah di Indonesia terkait kualitas hidup pasien hipertensi.

\section{DAFTAR PUSTAKA}

Adyani, I.F., 2008, Gambaran Kualitas Hidup Pasien Hipertensi Rawat Jalan RS PKU Muhammadiyah Yogyakarta Bulan Agustus Tahun 2006, Skripsi, Fakultas Farmasi Universitas Gajah Mada, Yogyakarta.

Anissa. 2013. Penilaian Kualitas Hidup pada Usia Lanjut Dengan Eq-5d Di Klub Jantung Sehat Kelurahan Pondok Kelapa Dan Faktor-Faktor Yang Mempengaruh. Universitas Indonesia. Tesis

Eidt-Koch D ${ }^{1}$, Mittendorf T, Greiner W. 2009. Cross-sectional validity of the EQ-5D-Y as a generic health outcome instrument in children and adolescents with cystic fibrosis in Germany. $\underline{B M C}$ Pediatr. 2009 Aug 28;9:55. doi: 10.1186/1471-2431-9-55.

Fitriana, N.A., \& Ambarini, T.K., 2012, Kualitas hidup pada penderita kanker serviks yang mengalami pengobatan radioterapi, Jurnal Psikologi Klinis dan Kesehatan Mental, Juni, 1, 2, 123-129.

Hartono, J.M., 2004, Metodologi Penelitian Bisnis : Salah Kaprah dan Pengalaman-Pengalaman, 120, 123-129.

Muhidin S.A., \& Abdurrahman M., 2007, Analisis Korelasi, Regresi, dan Jalur dalam Penelitian, 127128 , Pustaka Setia, Bandung.

Notoatmodjo, S, 2012, Metodologi Penelitian Kesehatan, Rineka Cipta, Jakarta, 152-154, 164-170. 
Nugroho I.S., 2010, Hubungan Pembelajaran Pendidikan Kewarganegaraan dengan Kesadaran Hukum Siswa X SMA Negeri Kartasura Tahun Ajaran 2008/2009, Skripsi, Fakultas Keguruan dan Ilmu Pendidikan Universitas Sebelas Maret, Surakarta.

Pickard S.A, Neary, M.Pand Cella D. 2007. Health and Quality of Life Outcomes Open Access Research Estimation of minimally important differences in EQ-5D utility and VAS scores in cancer Center for Pharmacoeconomic Research, Department of Pharmacy Practice, College of Pharma. Health and Quality of Life Outcomes 2007, 5:70 doi:10.1186/1477-7525-5-70.

Spilker B., 1996, Quality of Life and Pharmacoeconomics in Clinical Trials, 2nd ed, Lippincot Raven, Philadelphia, 58.

Setiati, S.,, Harimurti,K., Dewiasty E., Istanti R.,. 2010. Predictors and Scoring System for Healthrelated Quality of Life in an Indonesian Community - Dwelling Elderly Population. Department of Internal Medicine, Faculty of Medicine, University of Indonesia, Jl. Diponegoro No. 71 Jakarta 10430, Indonesia. Acta Med Indones-Indones J Intern Med.

Suharsimi A., 1998, Dasar-Dasar Evaluasi Pendidikan, 260, Bima Aksara, Jakarta.

Stark RG ${ }^{1}$, Reitmeir P, Leidl R, König HH. 2010. Validity, reliability, and responsiveness of the EQ5D in inflammatory bowel disease in Germany. Inflamm Bowel Dis. 2010 Jan;16(1):42-51. doi: 10.1002/ibd.20989.

Trevisol DJ et all, 2011, Health-related quality of life and hypertension: a systematic review and metaanalysis of observational studies. $J$ Hypertens. 29 (2) : 179-88. doi:10.1097/HJH.0b013e328340d76f.

Whynes, D. K., Does the correspondence between EQ-5D health state description and VAS score vary by medical condition? Whynes Health and Quality of Life Outcomes 2013, 11:155. 